\title{
Mental rotation is suppressed during saccadic eye movements
}

\author{
DAVID E. IRWIN and JAMES R. BROCKMOLE \\ University of Illinois at Urbana-Champaign, Champaign, Illinois
}

\begin{abstract}
We examined whether mental rotation is suppressed during saccadic eye movements. Subjects judged whether a character was normal or mirror-reversed while making no, short, or long saccades. Reaction time was longer under saccade than under no-saccade conditions and was longer when a long saccade rather than a short saccade was made, but only when the characters varied in orientation. These results indicate that mental rotation is suppressed during saccadic eye movements. The implications for theories of cognitive suppression during saccades are discussed.
\end{abstract}

People make rapid, saccadic eye movements about three or four times each second when they read, view pictures, or explore the world around them. The eyes are relatively still during the fixations that separate successive saccades. The average fixation is approximately $250-300 \mathrm{msec}$ in duration, whereas saccade duration depends on saccade distance. Saccade duration increases as saccade distance increases, but the average saccade duration during reading and picture viewing is approximately $30-50 \mathrm{msec}$ (Rayner, $1978,1998)$. Put another way, the eyes move about 3 times each second, 180 times each minute, 10,800 times each hour, and 172,800 times each 16-h waking day. If one assumes an average saccade duration of $30 \mathrm{msec}$, this means that the eyes are in motion about 90 min each day.

Saccadic suppression refers to the fact that visual sensitivity is reduced during saccades, so the acquisition of visual information from the environment is restricted largely to fixations (Matin, 1974; Volkmann, 1986; Zuber \& Stark, 1966). Thus, 90 min during the day when we think we are seeing, we actually are not. Recently, several investigators have argued that some cognitive processes are also suppressed during saccades, raising the possibility that 90 min during the day when we think we are thinking, we actually are not.

What is the evidence that cognitive processing may be suppressed during saccades? First, Sanders and Houtmans (1985) argued that stimulus encoding is suspended during saccades on the basis of the finding that the effects of degrading a stimulus (with a pattern mask) were fully maintained from one eye fixation to the next; in other words, no stimulus "clean-up" occurred while the

\footnotetext{
This research was supported by NSF Grant SBR $96-15988$ to D.E.I. We thank Paul Atchley, Laura Carlson-Radvansky, Angelique Hendricks, Jim Hoffman, Art Kramer, Gordon Logan, Jane Zbrodoff, and three anonymous reviewers for helpful comments on the research and Rob Gordon for technical assistance. Correspondence concerning this article should be addressed to D. E. Irwin, Department of Psychology, University of Illinois, 603 E. Daniel St., Champaign, IL 61820 (e-mail: dirwin@s.psych.uiuc.edu).
}

eyes were in motion (see also Sanders \& Rath, 1991). Second, Matin, Shao, and Boff (1993) found that informationprocessing time in a counting task increased when subjects had to execute saccades to acquire information from a display, suggesting that saccades interfere with central processing. Third, Van Duren (1993) reported that memory scanning in a Sternberg memory-scanning task is suspended during saccadic eye movements.

Most recently, Irwin and Carlson-Radvansky (1996) investigated whether mental rotation is suppressed during saccades. Subjects judged whether a letter presented in some orientation $\left(0^{\circ}, 90^{\circ}, 180^{\circ}\right.$, or $270^{\circ}$ from upright) was a normal or a mirror-image version of the letter (Cooper \& Shepard, 1973). Information about the identity and the orientation of the letter was provided while the subject fixated a leftward fixation mark, and then the subject executed a $15^{\circ}$ or a $45^{\circ}$ saccade to a rightward fixation mark. The target letter was presented at the rightward point, and the subject's reaction time (RT) and accuracy in making the normal/mirror-reversed judgment were recorded. Cooper and Shepard found that the more time subjects had to process the preview (identity and orientation) information, the less their judgments were affected by stimulus orientation; this improvement in performance was attributed to subjects' mentally rotating the preview to the desired orientation before the target was presented. On the basis of this, Irwin and Carlson-Radvansky expected that, if it is possible for people to perform mental rotation during eye movements, preview information presented before a saccade should be more beneficial when a $45^{\circ}$ saccade (which lasts about $100 \mathrm{msec}$ ), rather than a $15^{\circ}$ saccade (which lasts about $50 \mathrm{msec}$ ), was executed to the target letter. No such effect was found, however, even though a control condition showed that a 100 -msec preview was more beneficial than a 50-msec preview when the eyes did not move. Thus, Irwin and Carlson-Radvansky concluded that mental rotation does not occur during saccadic eye movements but, rather, is confined to discrete eye fixations.

There were several potential flaws in the experiment of Irwin and Carlson-Radvansky (1996), however. First, the 
conclusion that mental rotation is suppressed during saccades was based on a null effect (no difference in RTs between the $45^{\circ}$ saccade condition and the $15^{\circ}$ saccade condition). Second, saccade distance was blocked in their experiment, which might have led subjects to defer the initiation of mental rotation until the saccade had been completed; furthermore, subjects might have adopted different strategies when they knew they would be making long saccades, short saccades, or no saccades for a complete block of trials.

The purpose of the present study was to reexamine the question of whether mental rotation is suppressed during saccadic eye movements, while eliminating the potential flaws in the Irwin and Carlson-Radvansky (1996) study. In particular, the experimental procedure was modified in several ways. First, to reduce potential strategic effects on performance, saccade distance $\left(0^{\circ}, 7.5^{\circ}\right.$, or $\left.40^{\circ}\right)$ was sequenced randomly across trials. Second, to encourage subjects not to defer mental rotation until after saccade completion, two thirds of the experimental trials required no saccade (we call this the $0^{\circ}$ saccade condition), and when a saccade was required, the saccade target box was presented $300 \mathrm{msec}$ after the stimulus character was presented. Finally, the experimental task was modified so that suppression of mental rotation would produce a significant difference in RT, rather than a null effect. This was accomplished by presenting a single character (presented either $0^{\circ}, 90^{\circ}, 180^{\circ}$, or $270^{\circ}$ rotated from the upright, in either its normal or its mirror-reversed configuration) on the left side of the display and presenting the saccade target box either $7.5^{\circ}$ or $40^{\circ}$ away on the right side of the display and instructing the subjects to press one of two response buttons to indicate whether the character was normal or mirror-reversed while making a saccade to the target box. RT (measured from character onset) and accuracy were recorded. We reasoned that if mental rotation is suppressed during saccades, RT should be longer when subjects have to execute a $40^{\circ}$ saccade (which takes about $91 \mathrm{msec}$ ), as opposed to a $7.5^{\circ}$ saccade (which takes about $28 \mathrm{msec}$ ). In fact, if suppression is complete, RT should be $63 \mathrm{msec}$ longer in the $40^{\circ}$ condition than in the $7.5^{\circ}$ condition, because this is the difference in saccade duration $(91-28)$.

\section{EXPERIMENT}

\section{Method}

Subjects. Eight subjects participated in this experiment. All the subjects were students at the University of Illinois, and all were naive with respect to the experimental hypotheses. The subjects were paid $\$ 5$ per hour for their participation

Stimuli. The stimuli presented to the subjects were the characters R, J, G, 2.5, and 7, presented in Arial type font. Throughout the course of the experiment, two versions of each character were presented. In the normal version, characters were presented as they are properly written. In the mirror-reversed version, the characters were displayed rotated $180^{\circ}$ around their vertical axes. In addition, the characters were presented in one of four degrees of rotation (or orientations). These included upright $\left(0^{\circ}\right)$, on the character's right side $\left(90^{\circ}\right)$, upside down $\left(180^{\circ}\right)$, and on the character's left side $\left(270^{\circ}\right)$.
During the experiment, the subjects were seated $45 \mathrm{~cm}$ from the display monitor. At this viewing distance, the total display subtended $48^{\circ}$ of visual angle horizontally and $37^{\circ}$ vertically. In their normal upright orientation, the characters subtended a range from $0.8^{\circ}$ to $1.1^{\circ}$ horizontally, and all the characters subtended $1.3^{\circ}$ vertically. The characters were presented in a rectangular box subtending $3.0^{\circ}$ horizontally and $1.9^{\circ}$ vertically. The saccade targets were boxes of the same size. The sizes of the characters and the boxes did not vary with version or orientation. During the experiment, the characters were presented $20^{\circ}$ left of center. The saccade target boxes were presented either $12.5^{\circ}$ left of center (in the $7.5^{\circ}$ saccade condition) or $20^{\circ}$ right of center (in the $40^{\circ}$ saccade condition). The stimuli were presented in SVGA mode $(640 \times 480$ pixel resolution $)$. The display background was light gray (CIE coordinates: $x=.302, y=$ .318 , luminance $\left.=68 \mathrm{~cd} / \mathrm{m}^{2}\right)$, the letters were dark gray $(x=.306$, $y=.322$, luminance $\left.=17 \mathrm{~cd} / \mathrm{m}^{2}\right)$, and the boxes were white $(x=$ $.299, y=.314$, luminance $=149 \mathrm{~cd} / \mathrm{m}^{2}$ ).

Apparatus. The stimuli were presented at a refresh rate of $72 \mathrm{~Hz}$ on a NEC MultiSync 6FGp color monitor. A Gateway2000 486 microcomputer controlled stimulus presentation with an SVGA graphics adapter. The computer also recorded the output from an Applied Science Laboratories Model 210 scleral reflectance eyetracker by means of an analog-to-digital converter. The subjects responded by pressing hand-held microswitches interfaced with the computer via a digital input board. The eyetracker was mounted on eyeglass frames that were held in place on the subject's head by a headband. The eyetracker was configured to record horizontal movements of the left eye only. Eye position was sampled once each millisecond. A bite bar with dental impression compound was used to keep the subject's head steady during the experiment. The subjects completed a calibration sequence (described later) before every experimental trial. The accuracy of the eyetracker under these conditions was $\pm 0.3^{\circ}$.

Design. The experiment used a within-subjects design. On each trial, the subjects decided whether the stimulus presented was the normal or the mirror-reversed version, regardless of orientation. On two thirds of the trials, no saccade was required. On one sixth of the trials, a saccade of $7.5^{\circ}$ was elicited, and on one sixth of the trials, a $40^{\circ}$ saccade was elicited. Thus, this experiment employed a 2 (version) $\times 3$ (saccade distance) $\times 4$ (orientation) $\times 6$ (character) de sign. Version and character were treated as counterbalancing factors only and were not entered into any analyses.

Each subject completed five sessions, one per day. In order to be come familiar with the basic mental rotation task, in the first session each subject first completed two blocks of 48 trials each, during which the stimulus character was always presented at a central fixation point and no eye movements were required, and then several blocks of practice trials, in which no-saccade and saccade trials were intermixed as described in the preceding paragraph. Sessions 2-5 were experimental sessions, in which no-saccade and saccade trials were intermixed as described above; in each session, the subjects completed 10 practice trials, followed by two experimental blocks of 72 trials each. By the end of the experiment, each subject completed a total of eight blocks and 576 trials. Blocks $1-4$ and 5-8 represented one complete counterbalance of the experimental factors. In each counterbalance, each character was presented in each version and each degree of rotation four times under no-saccade conditions and one time for each saccade distance.

Procedure. The procedure is shown in Figure 1. A subject began each trial by completing a calibration routine during which a dark gray "+" sign (subtending $0.2^{\circ}$ horizontally and $0.4^{\circ}$ vertically) was presented serially in five locations, each separated by $10^{\circ}$ of visual angle. The subject's eye position was monitored during this procedure, which served to calibrate the output of the eyetracker against spatial position. Following the disappearance of the last calibration point, an empty white box appeared on the left side of the display monitor. The subjects fixated the center of this box for $1,500 \mathrm{msec}$; 
Calibration:

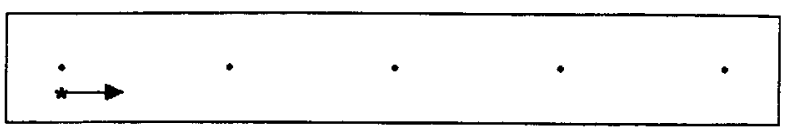

Fixation (1500 ms) :

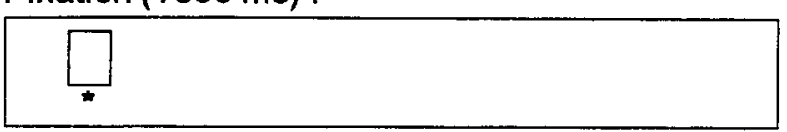

Stimulus :

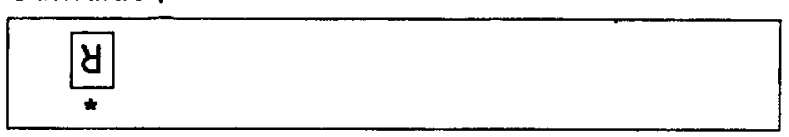

Normal/Mirror Response:

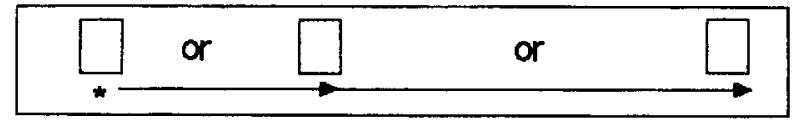

Figure 1. Schematic illustration of the procedure in Experiment 1 . The asterisk represents eye position. Following a calibration sequence, the subjects fixated a fixation box for 1,500 msec. Then a stimulus character was presented at some orientation for 300 msec. On two thirds of the trials, no saccade box was presented, so the subjects made their normal/mirror-reversed judgment about the character while maintaining fixation on the fixation box. On one sixth of the trials, a saccade box was presented $7.5^{\circ}$ to the right of fixation, and on another one sixth of the trials, a saccade box was presented $40^{\circ}$ to the right of fixation. When this happened, the subjects were instructed to make their nor$\mathrm{mal} / \mathrm{mirror}$ judgment while moving their eyes to the saccade box. Saccade distance $\left(0^{\circ}\right.$ vs. $7.5^{\circ}$ vs. $\left.4^{\circ}\right)$ varied randomly over trials.

then a character was presented in the box for $300 \mathrm{msec}$. Immediately after the offset of the character, a saccade target box was presented on one third of the trials, either $7.5^{\circ}$ or $40^{\circ}$ to the right of the fixation box. On two thirds of the trials, no saccade target box appeared, and the subjects were instructed to not move their eyes but to continue fixating where the letter had been presented. If a saccade target box did appear, the subjects were instructed to execute a saccade to that target and, while moving their eyes, decide which version of the character was presented. On all the trials, they were told to respond as quickly but as accurately as possible. The subjects pressed the switch in their dominant hand to indicate that the character was presented in its normal version and the switch in their nondominant hand to indicate that the character was mirror-reversed.

\section{Results and Discussion}

Discarded data. No-saccade $\left(0^{\circ}\right.$ saccade condition) trials in which the subject made an eye movement (typically a small shift of gaze within the stimulus character) were deleted from analysis $(6.7 \%$ of all the no-saccade trials), as were no-saccade trials in which an eyeblink occurred or in which the eyes were not within the fixation box when the stimulus character was presented $(4.8 \%$ of all no-saccade trials). Mean RT on these two classes of deleted trials was 771 and $756 \mathrm{msec}$, respectively, not significantly different from the mean RT of $755 \mathrm{msec}$ on the remaining $88.5 \%$ of the no-saccade trials that were accepted for analysis.

Saccade trials in which the subject made the normal/ mirror-reversed response before making an eye movement (10.0\% of all the saccade trials) and saccade trials in which an eyeblink occurred, the gaze shifted within the stimulus character, or the eyes were not within the fixation box when the stimulus character was presented (16.6\% of all the saccade trials) were also deleted from analysis. In total, $73.3 \%$ of the $7.5^{\circ}$ saccade trials and $73.4 \%$ of the $40^{\circ}$ saccade trials were accepted for analysis. Table 1 shows the percentages and mean RTs of accepted and discarded trials as a function of stimulus orientation for each saccade distance. These data are informative in several ways. First, the fact that the subjects sometimes made the normal/mirror-reversed response before moving their eyes indicates that they were processing the stimulus character during the $300-\mathrm{msec}$ period before the saccade target box was presented; that is, they did not defer mental rotation until after they knew whether they would have to make an eye movement. 'The fact that the proportion of trials in which the response was made before the saccade decreased with increasing stimulus misorientation (from $17.0 \%$ of the trials for upright stimuli to $8.5 \%$ of the trials for $90^{\circ}$ [including $270^{\circ}$ or $-90^{\circ}$ ] rotations to $4.2 \%$ of the trials for $180^{\circ}$ rotations, averaged over saccade distance) provides further evidence for this conclusion, since stimulus processing would be more likely to be completed if less mental rotation was required. Second, mean RT on trials in which the response was made before the saccade $(516 \mathrm{msec})$ was considerably faster than that on those trials in which the saccade occurred before the response $(910 \mathrm{msec})$, suggesting that saccades interfered with stimulus processing. There was no difference in mean RT between the $7.5^{\circ}$ saccade condition $(539 \mathrm{msec})$ and the $40^{\circ}$ saccade condition $(493 \mathrm{msec})$ when the response was made before the saccade, however, which suggests that the act of programming a long, as opposed to a short, saccade does not interfere with mental rotation.

The data for the trials that were discarded for eyeblinks or misfixations are rather noisy; a weak orientation effect is apparent, but not a systematic effect of saccade distance.

Accepted data. A preliminary analysis of the eye movement data showed that the mean initial fixation position of the eyes did not vary as a function of orientation or saccade distance $\left(0^{\circ}\right.$ vs. $7.5^{\circ}$ vs. $40^{\circ}$ saccade); on average, the eyes were fixated $0.1^{\circ}\left(S E=0.1^{\circ}\right)$ to the left of center of the fixation box. The mean distance of the initial saccade in the $7.5^{\circ}$ saccade condition was $7.9^{\circ}(S E=$ $\left.0.2^{\circ}\right)$, whereas it was $37.3^{\circ}\left(S E=0.8^{\circ}\right)$ in the $40^{\circ}$ saccade condition. Mean saccade duration was $28.1 \mathrm{msec}(S E=$ $0.9 \mathrm{msec}$ ) in the $7.5^{\circ}$ saccade condition and $90.8 \mathrm{msec}$ $(S E=3.5 \mathrm{msec})$ in the $40^{\circ}$ saccade condition. Saccade distance and saccade duration did not vary as a function of stimulus orientation.

Of primary interest is whether mental rotation performance was affected by saccade distance. If mental rotation 
Table 1

Experiment 1: Percentages and Mean Reaction Times (RTs, in Milliseconds) of Accepted and Discarded Trials as a Function of Stimulus Orientation for Each Saccade Distance

\begin{tabular}{|c|c|c|c|c|c|c|}
\hline \multirow[b]{2}{*}{ Orientation } & \multicolumn{2}{|c|}{ Accepted Trials } & \multicolumn{2}{|c|}{$\begin{array}{c}\text { Discarded Trials: } \\
\text { Response Before Saccade }\end{array}$} & \multicolumn{2}{|c|}{$\begin{array}{l}\text { Discarded Trials: } \\
\text { Blinks/Misfixations }\end{array}$} \\
\hline & $\%$ & RT & $\%$ & RT & $\%$ & RT \\
\hline \multicolumn{7}{|c|}{ Saccade Distance $=7.5^{\circ}$} \\
\hline $0^{\prime \prime}$ & 65.6 & 836 & 18.5 & 477 & 15.9 & 705 \\
\hline $90^{\prime \prime}$ & 75.3 & 834 & 9.6 & 548 & 15.2 & 823 \\
\hline $180^{\prime \prime}$ & 77.4 & 973 & 6.9 & 669 & 15.8 & 872 \\
\hline $270^{\prime \prime}$ & 76.2 & 850 & 7.2 & 460 & 16.6 & 765 \\
\hline \multicolumn{7}{|c|}{ Saccade Distance $=40^{\circ}$} \\
\hline $0^{\circ}$ & 63.6 & 899 & 15.5 & 465 & 20.8 & 786 \\
\hline $90^{17}$ & 77.5 & 920 & 3.9 & 494 & 18.5 & 815 \\
\hline $180^{\circ}$ & 83.1 & 1,030 & 1.5 & 512 & 15.4 & 834 \\
\hline $270^{\prime \prime}$ & 72.5 & 934 & 13.2 & 503 & 14.3 & 855 \\
\hline
\end{tabular}

is suppressed during saccades, $\mathrm{RT}$ should be longer when subjects have to execute a long saccade (which took, on average, $91 \mathrm{msec}$ ), as opposed to a short saccade (which took, on average, $28 \mathrm{msec}$ ). In contrast, if mental rotation is not suppressed during saccades, RT should be unaffected by saccade distance. Figure 2 shows the results (mean RT for correct trials only, measured from stimulus onset until response) as a function of saccade distance and stimulus orientation; also shown are the results from the nosaccade $\left(0^{\circ}\right.$ saccade $)$ control condition.

Analyses of variance (ANOVA) were conducted on the RT (correct trials only) and accuracy data, with saccade condition and stimulus orientation as factors. Mean RT was $742 \mathrm{msec}$ in the no-saccade ( $(0$ " saccade) condition. $873 \mathrm{msec}$ in the $7.5^{\circ}$ saccade condition, and $946 \mathrm{msec}$ in the $40^{\circ}$ saccade condition $\left[F(2,14)=26.9, M S_{\mathrm{c}}=12,396\right.$, $p<.001]$. The halfwidth of the $95 \%$ confidence interval for the difference between means was $53.8 \mathrm{msec}$, indicating that all pairwise differences were significant. The effect of stimulus orientation was also significant $[F(3,21)=$ $\left.8.2, M S_{\mathrm{c}}=14,659, p<.001\right]$, consistent with many previous studies. The interaction between saccade condition and stimulus orientation was also significant $[F(6,42)=$ 3.0, $\left.M S_{c}=1,901, p<.02\right]$, but an analysis excluding the no-saccade condition showed that the effect of stimulus orientation was the same in the 40 " saccade condition as that in the $7.5^{\circ}$ saccade condition $\left[F(3,21)=0.4, M S_{\mathrm{c}}=\right.$ $2.329, p>.7]$; this is consistent with the hypothesis that no mental rotation was taking place during the saccade. The significant interaction when the no-saccade condition is included arises because the difference between the saccade and the no-saccade conditions was larger when the stimulus was upright than when it was misoriented This is an artifact, however, caused by the fact that more trials were discarded on the basis of subjects' responding before moving their eyes when the stimulus was upright than when it was misoriented (see Table 1 and the discussion of the discarded data above). When the discarded data are included in the analysis, the interaction between saccade condition and stimulus orientation is no longer significant $[F(6,42)<1]$, even though the main effects of saccade condition and stimulus orientation are still significant.

Mean proportion correct on accepted trials did not vary with saccade condition $[M=.909 ; F(2,14)=0.66$, $\left.M S_{\mathrm{c}}=0.003, p>.5\right]$. It did vary with stimulus orientation, however $[M=.977, .937, .757$, and .967 for stimulus orientations of $0^{\circ}, 90^{\circ}, 180^{\circ}$, and $270^{\circ}$, respectively; $\left.F(3,21)=17.8, M S_{c}=0.015, p<.001\right]$. The interaction between saccade condition and stimulus orientation was not significant $\left[F(6,42)=1.0, M S_{\mathrm{e}}=0.003, p>.4\right]$.

These results indicate that mental rotation is suppressed during saccades. Mean RT was $73 \mathrm{msec}$ longer when the subjects had to execute a long $\left(40^{\circ}\right)$ saccade, as opposed to a short $\left(7.5^{\circ}\right)$ saccade, while attempting to perform mental rotation. Recall that the difference in saccade duration between $40^{\circ}$ and $7.5^{\circ}$ saccades was $63 \mathrm{msec}$; thus, our results suggest that mental rotation was completely suppressed while the eyes were moving. In addition, the requirement to make any saccade also appears to produce a large cost: Mean RT in the $7.5^{\circ}$ saccade condition was 131 msec longer than mean RT in the no-saccade condition. This large difference presumably reflects a combination of suppression of processing during the saccade plus a dual-task cost (i.e., in the saccade conditions, the subjects had to perform mental rotation and move their eyes, whereas in the no-saccade condition, they had only to perform mental rotation). ${ }^{2}$ Irwin (1998) found similar dual-task costs when subjects had to make saccades during word recognition and word identification tasks. Most important for present purposes, increasing saccade distance slowed processing even more, indicating that, in addition to a general dual-task cost, mental rotation is suppressed during the saccade.

To obtain additional information about the distribution of processing time in the saccade conditions, the eye movement record for each subject was analyzed, and the total RT on each trial (accepted trials only) was broken down into three component measures (Sanders, 1963, 1970): time left (TL), the time spent fixating the stimulus 


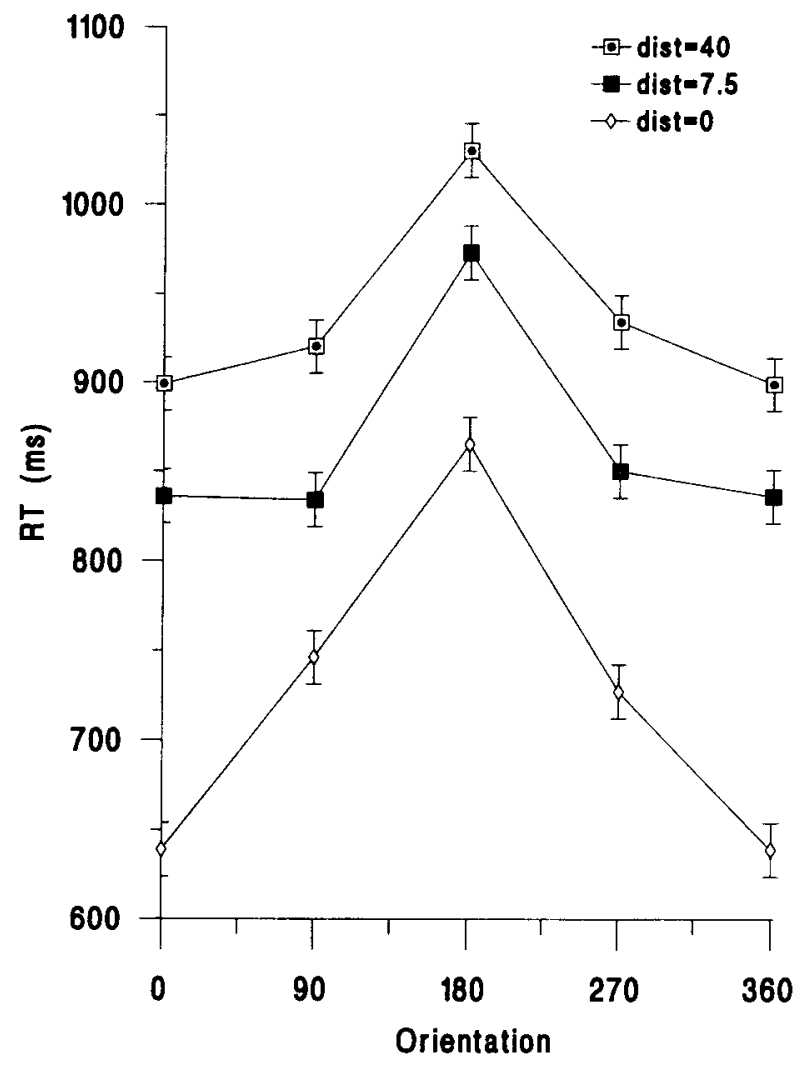

Figure 2. Reaction time (RT) as a function of stimulus orientation for $0^{\circ}$ (no-saccade), $7.5^{\circ}$, and $40^{\circ}$ saccade trials.

character before the saccade was initiated to the target box; time moving (TM), the duration of the saccade; and time right (TR), the time that elapsed between the subject's eye's landing on or near the target box and the subject's response (even though the subjects had been instructed to make their normal/mirror-reversed decision while their eyes were moving, on most trials they pressed the response button after their eyes had landed near the saccade target box).

Separate ANOVAs were conducted on the TL, TM, and TR components (from correct trials only), with saccade distance and stimulus orientation as factors. Mean $\mathrm{TL}$ (the time spent fixating the stimulus character before saccade onset) was shorter in the $40^{\circ}$ saccade condition $(M=507 \mathrm{msec})$ than in the $7.5^{\circ}$ saccade condition $[M=$ $\left.531 \mathrm{msec} ; F(1,7)=10.5, M S_{\mathrm{e}}=882.5, p<.02\right]$. The effect of stimulus orientation was also significant $[F(3,21)=$ 7.1, $M S_{\mathrm{e}}=192.0, p<.002$ ]; for unknown reasons, TL for characters rotated by $90^{\circ}$ was slightly shorter than TL for other orientations $(M=518,507,525$, and $527 \mathrm{msec}$ for orientations of $0^{\circ}, 90^{\circ}, 180^{\circ}$, and $270^{\circ}$, respectively). The interaction between saccade distance and stimulus orientation was not significant $\left[F(3,21)=1.5, M S_{\mathrm{e}}=\right.$ $403.4, p>.2]$. Note that the TL times included the 300 msec presentation of the stimulus that preceded the presentation of the saccade target box; the latency to initiate a saccade once the saccade target was presented was thus approximately $200-230 \mathrm{msec}$.

Mean saccade duration (TM) was longer in the $40^{\circ}$ saccade condition $(M=90.8 \mathrm{msec})$ than in the $7.5^{\circ}$ saccade condition $\left[M=28.1 \mathrm{msec} ; F(1,7)=243.7, M S_{\mathrm{e}}=258.4\right.$, $p<.001]$. There was no effect of stimulus orientation on $\mathrm{TM}\left[F(3,21)=2.3, M S_{\mathrm{e}}=7.4, p>.10\right]$, and the interaction between saccade distance and stimulus orientation also was not significant $\left[F(3,21)=2.2, M S_{\mathrm{e}}=9.0, p>.10\right]$.

Postsaccadic processing time (TR) was longer in the $40^{\circ}$ saccade condition $(M=347 \mathrm{msec})$ than in the $7.5^{\circ}$ saccade condition $(M=313 \mathrm{msec})$, but this difference was not significant $\left[F(1,7)=3.4, M S_{\mathrm{e}}=5,234.7, p>.10\right]$. TR varied significantly with stimulus orientation $[M=290$, 311,415 , and $305 \mathrm{msec}$ for orientations of $0^{\circ}, 90^{\circ}, 180^{\circ}$, and $270^{\circ}$, respectively; $F(3,21)=4.8, M S_{\mathrm{e}}=10,816.7$, $p<.01]$. The interaction between saccade distance and stimulus orientation was not significant $[F(3,21)=0.29$, $\left.M S_{\mathrm{e}}=1,690.4, p>.8\right]$.

In sum, averaging over stimulus orientations, the subjects spent $531 \mathrm{msec}$ fixating the stimulus (TL) in the $7.5^{\circ}$ saccade condition, $28 \mathrm{msec}$ moving their eyes from the fixation box to the saccade target box (TM), and then an additional $313 \mathrm{msec}$ before making their response (TR). In the $40^{\circ}$ saccade condition, the subjects spent $507 \mathrm{msec}$ fixating the stimulus (TL), $91 \mathrm{msec}$ moving their eyes from the fixation box to the saccade target box (TM), and then an additional $347 \mathrm{msec}$ before making their response (TR). These results indicate that in the $40^{\circ}$ condition, the subjects were not able to use the extra time during the longer saccade to reduce the time needed for stimulus processing in the pre- and postsaccadic fixation periods. Indeed, the effect of stimulus orientation on overall RT was almost fully reflected in the postsaccadic processing time (TR), suggesting that mental rotation was completely suspended during the eye movement.

One perhaps surprising finding in Experiment 1 is that saccades delayed $\mathrm{RT}$ even for upright $\left(0^{\circ}\right.$ rotation) stimuli; this seems counterintuitive, because these stimuli require no rotation to be categorized as normal or mirror-reversed. Because the upright stimuli appeared in the context of misoriented stimuli, however, it is possible that the subjects engaged in a mental rotation process on every trial, even when the stimulus was upright. Ilan and Miller (1994) found that RT to classify upright stimuli as normal or mirror-reversed was about $100 \mathrm{msec}$ slower when the upright stimuli appeared in the context of rotated stimuli than when they appeared in isolation. They called this the rotational uncertainty effect. They argued that because subjects are uncertain from one trial to the next whether mental rotation is required, they initiate a mental rotation stage of processing even for upright stimuli. Our finding in Experiment 1 that saccades delayed the processing of upright stimuli thus presumably reflects suspension of this mental rotation stage during the eye movement. Another possibility, however, is that some process other than mental rotation was suppressed during saccades; this was investigated in the next experiment. 


\section{EXPERIMENT 2}

To demonstrate that it was the process of mental rotation that was suspended during the saccade and not some other aspect of stimulus processing (such as stimulus encoding, response selection, or response execution), in Experiment 2 normal and mirror-reversed characters were always presented in an upright orientation $\left(0^{\circ}\right.$ rotation) while subjects executed no, short, and long saccades. Note that this task required all of the same stages of processing as those used in Experiment 1, except for mental rotation; that is, the character had to be encoded, a normal/mirror-reversed decision had to be made, and a response had to be selected and executed. Thus, if the saccade distance effect found in Experiment 1 was due to the saccade's interfering with some stage other than mental rotation, Experiment 2 should provide results similar to those of Experiment 1 . In contrast, our expectation was that there would be no difference in RT for short and long saccades in Experiment 2, because mental rotation was never required.

\section{Method}

Subjects. The subjects were the same as those in Experiment 1. They all completed Experiment 2 before completing Experiment 1, but for purposes of exposition, Experiment 1 has been reported first. The data from 1 subject were not used in the analyses reported below because excessive blinking caused missing data in some cells of the experimental design.

Stimuli. The stimuli used in Experiment 1 were also used in Experiment 2, except that orientation was not manipulated in Experiment 2 . Thus, all the characters were presented in an upright (or $0^{\circ}$ rotation) orientation.

Apparatus. The apparatus used in Experiment 1 was also used in Experiment 2.

Design. The experiment used a within-subjects design. The subjects engaged in the same classification task as that used in Experiment 1 . As in Experiment 1, two thirds of the trials were no-saccade $\left(0^{\circ}\right.$ saccade $)$ trials, one sixth were $7.5^{\circ}$ saccade trials, and one sixth were $40^{\circ}$ saccade trials.

This experiment required two sessions. The first familiarized the subjects with the task, and no data from this session are included in the analyses. In the second session, the subjects were presented with two experimental blocks of 72 trials, yielding 144 total trials. In each block, each character appeared in each version (normal vs. mirror-reversed) four times under no-saccade conditions and once at each saccade distance.

Procedure. The procedure was identical to that used in Experiment 1 , except that the stimulus character was always presented in an upright position and the stimulus onset asynchrony (SOA) between stimulus onset and the presentation of a saccade target box (on saccade trials) was reduced from 300 to $150 \mathrm{msec}$. This was done to ensure that stimulus processing would not be complete before the presentation of a saccade target; pilot testing showed that mean RT would be about $150 \mathrm{msec}$ faster in this experiment than in Experiment 1 (in which stimulus orientation varied over trials), so SOA was reduced by that amount. ${ }^{3}$

Trials were deleted from analysis if they did not satisfy the eye movement criteria described in Experiment $1 ; 7.6 \%$ of the $0^{\circ}$ (nosaccade) trials, $23.2 \%$ of the $7.5^{\circ}$ saccade trials, and $26.2 \%$ of the $40^{\circ}$ saccade trials were discarded in this experiment. As in Experiment 1, many of the discarded saccade trials were due to subjects' responding before they moved their eyes $\left(7.5 \%\right.$ of all $7.5^{\circ}$ saccade trials, mean RT $=439 \mathrm{msec} ; 8.8 \%$ of all $40^{\circ}$ saccade trials, mean $\mathrm{RT}=426 \mathrm{msec}$ ).

\section{Results and Discussion}

A preliminary analysis of the eye movement data showed that the mean initial fixation position of the eyes did not vary as a function of saccade distance $\left(0^{\circ} \mathrm{vs} .7 .5^{\circ}\right.$ vs. $40^{\circ}$ saccade); on average, the eyes were fixated $0.5^{\circ}$ $\left(S E=0.1^{\circ}\right)$ to the left of center of the fixation box. The mean distance of the initial saccade in the $7.5^{\circ}$ saccade condition was $8.5^{\circ}\left(S E=0.3^{\circ}\right)$, whereas it was $36.6^{\circ}$ $\left(S E=0.5^{\circ}\right)$ in the $40^{\circ}$ saccade condition. Mean saccade duration was $30.2 \mathrm{msec}(S E=0.4 \mathrm{msec})$ in the $7.5^{\circ} \mathrm{sac}$ cade condition and $88.0 \mathrm{msec}(S E=4.6 \mathrm{msec})$ in the $40^{\circ}$ saccade condition.

Of primary interest is whether RT to make the normal/ mirror-reversed judgment was affected by saccade distance. The answer is no. Mean RT in the $7.5^{\circ}$ saccade condition was $647 \mathrm{msec}$, whereas mean RT in the $40^{\circ} \mathrm{sac}-$ cade condition was $656 \mathrm{msec}$; this difference was not significant $\left[F(1,6)=0.06, M S_{\mathrm{e}}=9,799, p>.8\right]$. Mean RT in the no-saccade $\left(0^{\circ}\right.$ saccade) condition was $552 \mathrm{msec}$, which is significantly faster than performance in either saccade condition $\left[F(2,12)=4.7, M S_{\mathrm{e}}=5,006, p<.05\right]$. Mean accuracy did not differ across conditions $[F(2,12)=$ $1.5, M S_{\mathrm{e}}=0.002, p>.25$; mean proportion correct $=$ $.977, .949$, and .940 for distances of $0^{\circ}, 7.5^{\circ}$, and $40^{\circ}$, respectively]. In sum, as in Experiment 1, saccades produced a dual-task cost in RT; unlike Experiment 1, however, mean RT did not differ across saccade distances, indicating that processing was not suppressed while the eyes were moving. The major difference between the two experiments is that the first required mental rotation, whereas the second did not; thus, we conclude that it was the process of mental rotation that was suppressed during saccades in Experiment 1.

\section{GENERAL DISCUSSION}

The purpose of the present study was to reexamine the question of whether mental rotation is suppressed during saccadic eye movements, as Irwin and CarlsonRadvansky (1996) concluded. The experimental procedure eliminated potential flaws in the design used by Irwin and Carlson-Radvansky. The results indicate that mental rotation is indeed suppressed during saccades: RT to decide that a stimulus was normal or mirror-reversed was longer when subjects had to execute a long rather than a short saccade during stimulus processing, but only when mental rotation was required.

The results of the present study are consistent with two hypotheses that have been proposed to account for the suppression of cognitive processing during saccadic eye movements. One hypothesis attributes suppression to dual-task interference (Irwin \& Carlson-Radvansky, 1996; Irwin, Carlson-Radvansky, \& Andrews, 1995; Matin et al., 1993). Although eye movements may seem effortless and we usually are unaware that they are even occur- 
ring, it is nonetheless the case that whenever we are engaged in some task and moving our eyes we are in a dualtask situation. In such situations, sometimes interference occurs, and sometimes it does not. Very few studies have directly investigated the effect of requiring a saccade as a secondary task; one exception is Pashler, Carrier, and Hoffman (1993), who found that under some conditions, saccades did delay the execution of a concurrent task.

According to the dual-task hypothesis, suppression of cognitive processing during saccades should occur only when shared processing structures are called on. Although the generation of saccadic eye movements relies on a complex network of brain structures, the key cortical areas appear to be the frontal (and supplementary) eye fields and the posterior parietal cortex (Schall, 1995). Thus, the dual-task hypothesis predicts that cognitive tasks that require these same brain areas will be suppressed during saccades. Mental rotation is one such task, because several neurophysiological investigations have indicated that mental rotation is carried out in the parietal cortex (e.g., Alivisatos \& Petrides, 1997; Kosslyn, DiGirolamo, Thompson, \& Alpert, 1998; Peronnet \& Farah, 1989). In contrast, other processes, such as word recognition and word identification (Irwin, 1998) and response selection (Van Duren \& Sanders, 1995), do not rely on the parietal cortex (Posner \& McCandliss, 1993; Requin, Riehle, \& Seal, 1988), so according to the dualtask hypothesis, these tasks should not be suppressed during saccades, and indeed they are not. Another virtue of this dual-task hypothesis is that it can account for the differences that have been found between no-saccade and saccade conditions in these experiments.

Viewed from this perspective, the results of the present study are consistent with other dual-task studies that have found that mental rotation cannot be performed concurrently with certain tasks. For example, Bundesen, Larsen, and Farrell (1981) found that people cannot perform size scaling and mental rotation at the same time. Using a psychological refractory period paradigm, Van Selst and Jolicoeur (1994) and Ruthruff, Miller, and Lachmann (1995) found that mental rotation cannot be performed completely in parallel with other central processes. Band and Miller (1997) found that mental rotation interferes with response preparation. Wohlschläger and Wohlschläger (1998) found that concordant hand movements (i.e., rotating a knob in the same direction as an imagined rotation of a visual stimulus) facilitated mental rotation, whereas discordant hand movements inhibited mental rotation (see also Wexler, Kosslyn, \& Berthoz, 1998).

Although the results of the present study are consistent with the dual-task hypothesis, they are also consistent with an attentional suppression hypothesis (Irwin, 1998); according to this hypothesis, automatic processes continue to operate during saccades, whereas attended processes do not (Irwin \& Carlson-Radvansky, 1996; Irwin et al., 1995). Mental rotation is a slow, effortful, and, hence, attention-demanding task, and it is suppressed during saccades, whereas automatic pathway priming (Irwin et al., 1995) and lexical processing (Irwin, 1998) are not. Van Duren and Sanders (1995) found that incompatible response assignments could be made during saccades, however, and this is inconsistent with the attentional suppression hypothesis. Thus, additional research is needed to discriminate further between the attentional suppression and the dual-task hypotheses of cognitive suppression during saccades.

\section{REFERENCES}

Alivisatos, B., \& Petrides, M. (1997). Functional activation of the human brain during mental rotation. Neuropsychologia, 35, 111-118.

BAND, G., \& MILLER, J. (1997). Mental rotation interferes with response preparation. Journal of Experimental Psychology: Human Perception \& Performance, 23, 319-338.

Bundesen, C., Larsen, A., \& Farrell, J. (1981). Mental transformations of size and orientation. In J. [B.] Long \& A. [D.] Baddeley (Eds.), Attention and performance IX (pp. 279-294). Hillsdale, NJ: Erlbaum.

CoOper, L. A., \& Shepard, R. N. (1973). Chronometric studies of the rotation of mental images. In W. G. Chase (Ed.), Visual information processing (pp. 76-176). New York: Academic Press.

IlAN, A., \& MilLER, J. ( 1994). A violation of pure insertion: Mental rotation and choice RT. Journal of Experimental Psychology: Human Perception \& Performance, 20, 520-536.

IRwiN, D. E. (1998). Lexical processing during saccadic eye movements. Cognitive Psychology, 36, 1-27.

Irwin, D. E., \& Carlson-Radvansky, L. A. (1996). Cognitive suppression during saccadic eye movements. Psychological Science, 7 , 83-88.

Irwin, D. E., Carlson-Radvansky, L. A., \& Andrews, R. V. (1995). Information processing during saccadic eye movements. Acta Psychologica, 90, 261-273.

Kosslyn, S. M., Digirolamo, G. J., Thompson, W. L., \& Alpert, N. M. (1998). Mental rotation of objects versus hands: Neural mechanisms revealed by positron emission tomography. Psychophysiology, 35, 151-161

MATIN, E. (1974). Saccadic suppression: A review and an analysis. Psychological Bulletin, 81, 899-917

Matin, E., Shao, K. C., \& Boff, K. R. (1993). Saccadic overhead: Information-processing time with and without saccades. Perception \& Psychophysics, 53, 372-380.

Pashler, H., Carrier, M., \& Hoffman, J. (1993). Saccadic eye movements and dual-task interference. Quarterly Journal of Experimental Psychology, 46A, 51-82.

Peronnet, F., \& Farah, M. J. (1989). Mental rotation: An eventrelated potential study with a validated mental rotation task. Brain \& Cognition, 9, 279-288.

Posner, M., \& McCandliss, B. (1993). Converging methods for investigating lexical access. Psychological Science, 4, 305-309.

RAYNER, K. (1978). Eye movements in reading and information processing. Psychological Bulletin, 85, 618-660.

RAYNER, K. (1998). Eye movements in reading and information processing: Twenty years of research. Psychological Bulletin, 124, 372-422.

Requin, J., Riehle, A., \& Seal, J. (1988). Neuronal activity and information processing in motor control: From stages to continuous flow. Biological Psychology, 26, 179-198.

Ruthruff, E., Miller, J., \& Lachmann, T. (1995). Does mental rotation require central mechanisms? Journal of Experimental Psychology: Human Perception \& Performance, 21, 552-570.

SANDERS, A. F. (1963). The selective process in the functional visual field. Assen, The Netherlands: Van Gorcum.

Sanders, A. F. (1970). Some aspects of the selective process in the functional visual field. Ergonomics, 13, 101-117. 
Sanders, A. F. \& Houtmans, M. J. M. (1985). There is no central stimulus encoding during saccadic eye shifts: A case against general parallel processing notions. Acta Psychologica, 60, 323-338.

Sanders. A. F., \& Rath, A. M. (1991). Perceptual processing and speed-accuracy trade-off. Acta $P_{\text {sychologica, }}$ 77, 275-291.

SCHAl.L, J. D. (1995). Neural basis of saccade target selection. Reviews in the Neurosciences, 6, 63-85.

ShePard, R. N., \& COOPER, L. A. (1982). Mental images and their transformations. Cambridge, MA: MIT Press.

VAN DurEn, L. (1993). Central stimulus processing during saccadic eye movements. In G. d'Ydewalle \& J. Van Rensbergen (Eds.), Perception and cognition: Advances in eve-movement research (pp. 23-35) Amsterdam: North-Holland.

VAN DUREN, L., \& SANDERS, A. F. (1995). Signal processing during and across saccades. Acta Psvchologica, 89, 121-147.

VAN Selst, M., \& Jolicoeur, P. (1994). Can mental rotation occur before the dual-task bottleneck? Journal of Experimental Psychology: Human Perception \& Performance, 20, 905-921.

Vol.KMANN, F. C. (1986). Human visual suppression. Vision Research, 26, 1401-1416.

Wexler, M., Kosslyn, S. M., \& Berthoz, A. (1998). Motor processes in mental rotation. Cognition, 68, 77-94.

WOHLSCHLÄGER. A., \& WOHLSCHLÄGER, A. (1998). Mental and manual rotation. Journal of Experimental Psychology: Human Perception \& Performance, 24, 397-412.

ZUBER, B. L., \& STARK. L. (1966). Saccadic suppression: Elevation of visual threshold associated with saccadic eye movements. Experimental Neurology, 16, 65-79

\section{NOTES}

1. Additional evidence that the subjects did not delay stimulus processing until after the saccade target box had been presented is provided by a comparison between performance in the pure no-saccade blocks that the subjects completed during the first session and performance in the experimental blocks in which no-saccade and saccade trials were intermixed. If the subjects deferred stimulus processing until after the saccade target box had been presented, mean RT in the mixed (experimental) blocks should be $300 \mathrm{msec}$ longer than that in the pure no-saccade blocks, because the saccade target box (when it was presented) was presented $300 \mathrm{msec}$ after stimulus onset. In fact. mean RT in the mixed (ex- perimental) blocks was faster $(854 \mathrm{msec})$ than that in the pure nosaccade blocks ( $984 \mathrm{msec}$ )

2. An astute reviewer observed that a sudden onset (the saccade target box) appeared in the visual periphery on saccade trials, but not on no-saccade trials, and suggested that these sudden onsets, rather than the saccades per se, might have interfered with mental rotation by capturing spatial attention. To investigate this, 8 subjects completed a control experiment, using the sarie stimuli and the same general design as those in Experiment 1, in which two thirds of the trials included only the stimulus presentation at $20^{\circ}$ left of center, whereas one third of the trials presented in addition a target box either $7.5^{\circ}$ or $40^{\circ}$ to the right of the stimulus after an SOA of $300 \mathrm{msec}$. Although target boxes were presented on one third of the trials, no saccades were made to them. Instead, the subjects were instructed to maintain fixation on the stimulus box and to indicate as quickly and as accurately as possible whether the stimulus character was normal or mirror-reversed and then to indicate (without speed stress) whether a target box had been presented and, if so, its location. Thus, onsets were presented, and the subjects had to attend to them, but they did not move their eyes to them. Mean correct RT for the normal/mirror-reversed response was $755 \mathrm{msec}$ when no target box was presented, $752 \mathrm{msec}$ when a target box was presented $7.5^{\circ}$ away from the stimulus, and $746 \mathrm{msec}$ when a target box was presented $40^{\circ}$ away from the stimulus. An ANOVA showed no effect of target location $(F<1)$ and no interaction between target location and stimulus orientation $[F(6.42)=1.6]$. Accuracy at reporting the presence and location of the target box exceeded $99 \%$. Given these results, we conclude that the mere onset of the saccade target box did not influence RT in this task. Thus, mental rotation was suppressed by saccades in Experiment 1 , rather than by the onset of the saccade target.

3. We also conducted pilot versions of this experiment, using SOAs of 0 and $300 \mathrm{msec}$. In each version, we found that saccade distance had no effect on RT or error rate. Over half of the trials had to be discarded when an SOA of $300 \mathrm{msec}$ was used, because the subjects responded before moving their eyes. We report the results of the 150 -msec SOA condition because saccades in this condition appeared to interrupt processing at approximately the same time before the normal/mirror-reversed response as the saccades in Experiment 1

(Manuscript received February 24, 1999; revision accepted for publication October 28, 1999.) 